\title{
Metodologias ativas associadas ao uso de tecnologias no âmbito educional: produções científicas de enfermagem uma revisão integrativa de literatura
}

\author{
Lívia Biasuz Machado* \\ Igor de Oliveira Lopes** \\ Rithiely Allana Bárbaro** \\ Kátia Fernanda Souza de Souza** \\ Isabel Cristina Wingert** \\ Júnior Felipe Luft**
}

\section{Resumo}

\begin{abstract}
Apresentar um novo método de abordagem de ensino pode, inicialmente, gerar aceitação negativa por parte do corpo docente e dos acadêmicos, pois a resistência ao novo é difícil de ser contornada. Para tanto, aliar modelos como metodologias ativas e tecnologias ao currículo educacional de enfermagem pode facilitar o processo de ensino-aprendizagem de discentes. Trata-se de uma revisão integrativa de literatura nos bancos de dados SCIELO e LILACS, de 2013 a 2017, acerca das discussões sobre metodologias ativas e tecnologias no âmbito da educação. Foram selecionados 29 artigos, segundo critérios, criando duas categorias de análise. Concluiu-se que o uso de metodologias ativas associadas à tecnologia permite o processo de ensino-aprendizado de forma crítica e reflexiva, que as tecnologias por si só não garantem melhorias do ensino, que as habilidades e o protagonismo discente e docente contribuem nesse processo e os currículos integrados possibilitam melhor interação das áreas.
\end{abstract}

Palavras-chaves: Aprendizagem significativa; Tecnologia da Educação; Metodologias Ativas; Enfermagem, Aprendizagem baseada em problemas.

\footnotetext{
* Enfermeira Sanitarista. Doutoranda Universidade Feevale. E-mail: (liviabmachado@gmail.com)

** Acadêmicos de Enfermagem Universidade Feevale.
} 


\title{
Active methodologies associated with the use of educational technologies: scientific productions of nursing an integrating literature review
}

\section{Abstract}

\begin{abstract}
Presenting a new method of teaching approach may initially generate negative acceptance by faculty and scholars, as resistance to the new is difficult to circumvent. To ally models as active methodologies and technologies to the nursing educational curriculum can facilitate the process of teaching students learning. This is an integrative review of literature, in the SCIELO and LILACS databases, from 2013 to 2017 on the discussions on active methodologies and technologies in the field of education. We selected 29 articles according to criteria generating two categories of analysis. It was concluded that the use of active methodologies associated to technology allows the process of teaching learning in a critical and reflexive way, that technologies alone do not guarantee improvements in teaching, that the abilities and the student and teaching protagonism contribute in this process and the curricula allow for better interaction of areas.
\end{abstract}

Keywords: Meaningful learning; Education Technology; Active Methodologies; Nursing, Problem-based learning.

\section{Metodologías activas asociadas al uso de tecnologías en el ámbito educional: producciones científicas de enfermar una revisión integral de literatura}

\section{Resumen}

La presentación de un nuevo método de enfoque de la enseñanza puede, inicialmente, generar aceptación negativa por parte del cuerpo docente y de los académicos, pues la resistencia al nuevo es difícil de ser contorneada. Para ello, aliar modelos como metodologías activas y tecnologías al currículo educativo de enfermería puede facilitar el proceso de enseñanza aprendizaje de los discentes. Se trata de una revisión integrativa de literatura, en los bancos de datos SCIELO y LILACS, de 2013 a 2017 sobre las discusiones sobre metodologías activas y tecnologías en el ámbito de la educación. Se seleccionaron 29 artículos según criterios generando 
dos categorías de análisis. Se concluyó que el uso de metodologías activas asociadas a la tecnología permite el proceso de enseñanza aprendido de forma crítica y reflexiva, que las tecnologías por sí solas no garantizan mejoras de la enseñanza, que las habilidades y el protagonismo discente y docente contribuyen en este proceso y los los currículos integrados posibilitan una mejor interacción de las áreas.

Palabras claves: Aprendizaje significativo; Tecnología de la Educación; Metodologías Activas; Enfermería, Aprendizaje basado en problemas.

\section{Introdução}

Algumas mudanças ocorridas na educação superior, no Brasil, foram presenciadas nos anos 1990, entre elas, a reformulação curricular dos cursos de graduação, sendo essa fomentada pelas Diretrizes Curriculares Nacionais para os Cursos de Graduação. Tais mudanças dos cursos na área da saúde estão relacionadas estreitamente com a proposta de novos perfis de profissionais que, por sua vez, viabilizem a consolidação do Sistema Único de Saúde (SUS). ${ }^{1}$ A mudança educacional de formação da enfermagem necessitava igualmente romper com a hegemonia ancorada apenas no modelo clínico abarcado de modelos advindos da educação bancária tradicional (e curativista-hospitalocêntrica), assim como, direcionar o foco de formação para profissionais que assistam à saúde de forma integral (PADOVANI; CORRÊEA, 2017).

Desde então, observam-se diversas iniciativas no intuito de modificar os modos de se educar na saúde, possibilitando aos discentes uma nova abordagem de ensino. Abordagem essa que utiliza métodos ativos de aprendizagem, aplicando o uso da tecnologia e de propostas mais autônomas focadas na aprendizagem significativa e na fundamentada em problemas. Igualmente, essa nova prática pode e deve ser direcionada para as práticas de promoção e atenção à saúde em comunidades, objetivando o conhecimento e a aplicação deste como autonomia dos sujeitos envolvidos. Isso envolve o enfermeiro em práticas atrativas a tal construção, e a exemplo das metodologias ativas de aprendizagem.

${ }^{1}$ São exemplos o VER-SUS, o PET-Saúde entre outros. 
Segundo Berbel (2011), faz-se necessária a criação de um ambiente favorável à aprendizagem, proporcionando aos acadêmicos e à comunidade a busca por novos caminhos, possibilidades do aprender e de novas metodologias de ensino, sendo estas vinculadas à tecnologia, em que as mesmas tenham o aprendizado do aluno foco, podendo assim motivar e promover a autonomia dos discentes.

De acordo com Ausubel (1968), a aprendizagem significativa dentro do ensino necessita de sentido ao acadêmico, e nesse processo os conceitos relevantes e as informações devem interagir e se ancorar em seus saberes e experiências prévias, ou seja, nos subsunçores. Da mesma forma que educar a comunidade como prática social exige ampliação para o contexto em que esta é inserida, têm as metodologias ativas o papel de movimentar práticas tradicionais também na promoção da saúde.

Métodos ativos de aprendizagem pressupõem uma sólida formação pedagógica, psicológica e teórica, para que seja possível conhecer claramente a natureza do ato pedagógico, e, por fim, podê-lo compreender como uma prática social e de experiências pessoais e que se fundamenta no científicos (ROSSO, 1992).

A verdadeira aprendizagem acontece quando o sujeito é transformado, ou seja, o conhecimento transmitido é reestruturado pelos professores, profissionais da saúde e pelos acadêmicos e, a partir dessa reestruturação, os mesmos se tornam autônomos, emancipados e independentes (FREIRE, 1996).

Entretanto, apresentar um novo método de abordagem de ensino pode, inicialmente, gerar aceitação negativa por parte do corpo docente e dos acadêmicos, pois a resistência ao novo é difícil de ser contornada. Uma solução tecnológica que busca essa integração é a utilização de simuladores. Segundo Ziv et al. (2005), simuladores utilizados para o ensino na área da saúde podem ser compreendidos como ferramentas que permitem aos educadores manter total controle em cenários clínicos pré-selecionados, descartando, nessa fase de aprendizagem, os riscos potenciais ao paciente (BEZ, 2013). 
Contudo, essa trajetória de novas metodologias, com o avanço dos movimentos sociais, exigiu que os profissionais de saúde direcionassem novas ações para as práticas assistenciais. Práticas essas devendo ser inclusivas, geradoras de autonomia e de pensamento crítico por parte de profissionais da saúde e dos protagonistas da comunidade.

\section{Metodologia}

Trata-se de um estudo de revisão integrativa de literatura, considerando os preceitos de Cooper (1982), o qual se estrutura em cinco etapas: formulação do problema (ou questão problematizadora), coleta dos dados, avaliação dos dados coletados, análise e interpretação dos mesmos, apresentação dos resultados e/ ou discussão conjuntamente.

A revisão integrativa de literatura permite a síntese de conhecimentos, inclui ainda a análise de pesquisas relevantes, as quais norteiam a tomada de decisão e assim melhorias na prática clínica, possibilitando sintetizar o estado do conhecimento de determinado assunto, além de indicar lacunas do conhecimento que necessitam ser preenchidas com a continuidade e realização de novos estudos científicos (MENDES, SILVEIRA, GALVÃO, 2008; COOPER, 1982).

O estudo se deteve ao banco de dados Literatura LatinoAmericana em Ciências de Saúde (LILACS) e no portal de revistas Scientific Electronic Library Online (SCIELO). As palavras-chave escolhidas para a busca foram: metodologias ativas, aprendizagem significativa e aprendizagem baseada em problema. Não foram construídas string de busca (com os termos AND, NOT ou OR), pois o uso dessas palavras-chave possibilitou identificar artigos que se aproximavam da temática da mesma forma que responderam à questão problematizadora após filtros específicos.

Como problematização, questionou-se: Quais as discussões feitas pelos autores, dos artigos selecionados, acerca das metodologias ativas associadas à tecnologia utilizada no âmbito 
educacional em produções de enfermagem? Para o refinamento da busca, foram considerados como critérios de inclusão, além das palavras-chave já descritas: artigos publicados entre 2013 e 2017 (buscando o estado da arte), gratuitos, completos, em língua portuguesa e da área da enfermagem. Os artigos em duplicidade foram contabilizados no portal de revistas SCIELO.

No banco de dados LILACS foram encontrados, com a palavra-chave metodologias ativas, 157 artigos, com aprendiragem significativa, 491 artigos e com aprendizagem baseada em problemas, 508 artigos, totalizando 1.156 produções. No portal de revistas SCIELO, foram encontrados, com a palavra-chave metodologias ativas, 126 artigos, com aprendizagem significativa, 454 artigos e com aprendizagem baseada em problema, 203 artigos, totalizando 783 produções. A soma das produções selecionadas em ambos os locais gerou um total de 1.939 produções. Aplicaram-se os critérios de exclusão: duplicidade, fora do período determinado, não gratuitos, incompletos, não sendo em língua portuguesa e não sendo produção da área da enfermagem. Após o filtro, restaram 46 artigos. Depois da primeira leitura flutuante, na qual foram observados os títulos e os resumos, foram excluídos 16 artigos por não serem relevantes à temática ou não se aproximarem da problemática de pesquisa, restando 30 produções. Dessas 30, após leitura detalhada com o propósito de responder à problemática, foi ainda excluído um artigo, restando 29 produções.

O passo a passo do refino é descrito no fluxograma 1, Prisma, representado na Figura 1: 
Registros achados com a palavrachave: Aprendizagem Significativa

( $n=454$ gcielo +491 lilacs)
Registros achados com a palaurachave: Aprendizagem Baseada em Problemas $(n=203$ scielo +508 lilacs)
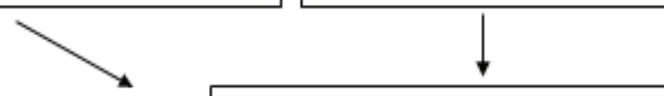

(a)

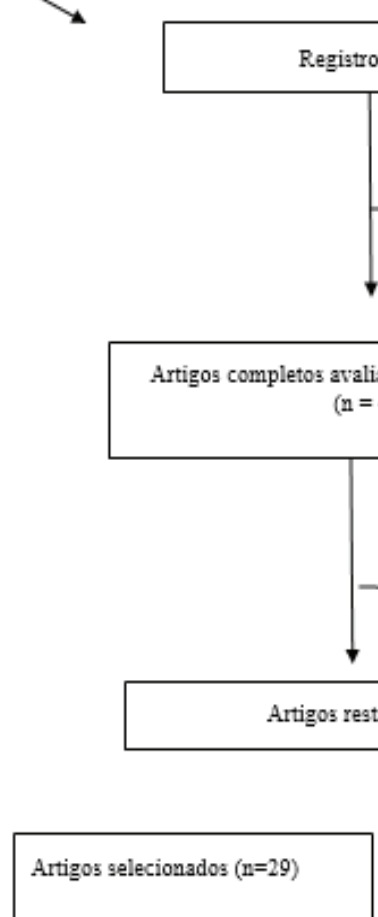

Registros excluidos por duplicidade, fora do periodo, não-gratuitos, incompletos, não gendo português e não ser da área da enfermagem $(n=1893)$

Artigos completos avaliados para elegibilidade $(n=46)$

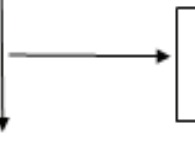

Registros descartados em leitura flutuante $(n=16)$

Fonte: http://prisma-statement.org/PRISMAStatement/FlowDiagram.aspx (MOHER, 2009).

A descrição dos artigos selecionados é apresentada no quadro sinóptico (Quadro 1), no qual é contemplado o título do artigo, autor(es), ano e base de dados: 


\begin{tabular}{|c|c|c|c|c|}
\hline $\mathbf{N}^{\circ}$ & Título do Artigo & Autores & Ano & Base de dados/portal \\
\hline 01 & $\begin{array}{l}\text { A experiência da educação } \\
\text { permanente como estraté- } \\
\text { gia de gestão com os auxi- } \\
\text { liares de enfermagem }\end{array}$ & $\begin{array}{l}\text { Pereira MV, Bar- } \\
\text { bosa VBA, J.R.S } \\
\text { Vernasque. }\end{array}$ & 2014 & $\begin{array}{l}\text { Lilacs } \\
\text { http://www.reme.org.br/ } \\
\underline{\text { artigo/detalhes/921 }}\end{array}$ \\
\hline 02 & $\begin{array}{l}\text { A pedagogia vivencial } \\
\text { humanescente e a teoria } \\
\text { da aprendizagem }\end{array}$ & $\begin{array}{l}\text { Alves KYA, San- } \\
\text { tos VEP, Dantas } \\
\text { MSP, Martins } \\
\text { CCF, Salvador } \\
\text { PTCO, Assis } \\
\text { YMS. }\end{array}$ & 2015 & $\begin{array}{l}\text { Lilacs } \\
\text { https://revistas.ufpr.br/co- } \\
\text { gitare/article/view/3971 } 3\end{array}$ \\
\hline 03 & $\begin{array}{l}\text { A utilização do lúdico } \\
\text { como estratégia de inova- } \\
\text { ção no ensino da enfer- } \\
\text { magem }\end{array}$ & $\begin{array}{l}\text { Souza JB, Colliselli } \\
\text { L., Madureira VSF. }\end{array}$ & 2017 & $\begin{array}{l}\text { Lilacs } \\
\text { http://www.seer.ufsj.edu. } \\
\text { br/index.php/recom/arti- } \\
\text { cle/view/1227 }\end{array}$ \\
\hline 04 & $\begin{array}{l}\text { Aplicação do mapa con- } \\
\text { ceitual: resultados com } \\
\text { diferentes métodos de } \\
\text { ensino-aprendizagem }\end{array}$ & $\begin{array}{l}\text { Carvalho DPSRP, } \\
\text { Barichello AFVE, } \\
\text { Villar RLA, Santos } \\
\text { VEP, Ferreira-Ju- } \\
\text { nior AM. }\end{array}$ & 2016 & $\begin{array}{l}\text { Lilacs } \\
\text { http://www.redalyc.org/ar- } \\
\underline{\text { ticulo.oa?id=74147078009 }}\end{array}$ \\
\hline 05 & $\begin{array}{l}\text { Aprendizagem em saúde } \\
\text { mental por meio da pro- } \\
\text { dução vídeo gráfica: relato } \\
\text { de experiência }\end{array}$ & $\begin{array}{l}\text { Machado DM, } \\
\text { Göttems LBD, } \\
\text { Pires MRGM. }\end{array}$ & 2013 & $\begin{array}{l}\text { Scielo (Lilacs)* } \\
\text { http://www.scielo.br/ } \\
\text { scielo.php?script=s- } \\
\text { ci arttext\&pid=S0104- } \\
07072013000400040\end{array}$ \\
\hline 06 & $\begin{array}{l}\text { Autonomia do graduando } \\
\text { em enfermagem na (re) } \\
\text { construção do conhe- } \\
\text { cimento mediado pela } \\
\text { aprendizagem baseada em } \\
\text { problemas }\end{array}$ & $\begin{array}{l}\text { Campos LRG, } \\
\text { Ribeiro MRM, } \\
\text { Depes VBS. }\end{array}$ & 2014 & $\begin{array}{l}\text { Scielo (Lilacs)* } \\
\text { http://www.scielo.br/scielo. } \\
\text { php?pid=S0034-71672014 } \\
\text { 000500818\&script=sci ab- } \\
\text { stract\&tlng=pt }\end{array}$ \\
\hline 07 & $\begin{array}{l}\text { Avaliação da implantação } \\
\text { do currículo integrado no } \\
\text { programa de graduação } \\
\text { em enfermagem }\end{array}$ & $\begin{array}{l}\text { Ide CAC, Arantes } \\
\text { LS, Mendonça } \\
\text { MC, Silva VR, Del } \\
\text { Corona ARP. }\end{array}$ & 2014 & $\begin{array}{l}\text { Scielo (Lilacs)* } \\
\text { http://www.scielo.br/scielo. } \\
\text { php?pid=S0103-21002014 } \\
\text { 000400009\&script=sci ab- } \\
\text { stract\&tlng=pt }\end{array}$ \\
\hline
\end{tabular}




\begin{tabular}{|c|c|c|c|c|}
\hline 08 & $\begin{array}{l}\text { Avaliação de tecnologia } \\
\text { digital educacional "Sinais } \\
\text { Vitais e Anatomia" por } \\
\text { estudantes da educação } \\
\text { profissionalizante em } \\
\text { enfermagem }\end{array}$ & $\begin{array}{l}\text { Góes FSN, Ca- } \\
\text { margo RAA, } \\
\text { Fonseca LMM, } \\
\text { Oliveira GF, Hara } \\
\text { CYN, Felipe HR, } \\
\text { Caldas NB. } \\
\end{array}$ & 2015 & $\begin{array}{l}\text { Lilacs } \\
\text { http://www.reme.org.br/ } \\
\underline{\text { artigo/detalhes/1004 }}\end{array}$ \\
\hline 09 & $\begin{array}{l}\text { Avaliação de uma tecno- } \\
\text { logia educacional para a } \\
\text { avaliação clínica de recém- } \\
\text { nascidos prematuros }\end{array}$ & $\begin{array}{l}\text { Fonseca LMM, } \\
\text { Natália Leite } \\
\text { DAAM, Santos } \\
\text { CB, Lima RAG, } \\
\text { Scochi CGC. }\end{array}$ & 2013 & $\begin{array}{l}\text { Scielo } \\
\text { http://www.scielo.br/scielo. } \\
\text { php?pid=S0104-1169201 } \\
\underline{30001000} \\
\text { 11\&script=sci arttext } \\
\text { \&tlng=pt }\end{array}$ \\
\hline 10 & $\begin{array}{l}\text { Casos de papel e role play: } \\
\text { estratégias de aprendiza- } \\
\text { gem em enfermagem }\end{array}$ & $\begin{array}{l}\text { Cogo ALP, Dal } \\
\text { Pai D., Aliti GB, } \\
\text { Hoefel HK, Azzo- } \\
\text { lin KO, Busin L., } \\
\text { Unicovsky MAR, } \\
\text { Kruse MHL. } \\
\end{array}$ & 2016 & $\begin{array}{l}\text { Lilacs } \\
\text { https://scielo.conicyt. } \\
\underline{\text { cl/scielo.php?script }=} \\
\underline{\text { sci arttext\&pid }=S 0717-} \\
\underline{955320} \\
\underline{13000300003}\end{array}$ \\
\hline 11 & $\begin{array}{l}\text { Construção de um "Vê de } \\
\text { Gowin" para a análise de } \\
\text { produções acadêmicas de } \\
\text { enfermagem }\end{array}$ & $\begin{array}{l}\text { Silva CC, Oliveira } \\
\text { AKS, Egry EY, } \\
\text { Neto EAL, Anjos } \\
\text { UU, Silva ATMC. }\end{array}$ & 2013 & $\begin{array}{l}\text { Scielo } \\
\text { http://www.scielo.br/ } \\
\text { scielo.php?pid }=S 0080- \\
\text { 62342013000300709\& } \\
\text { script }=\text { sci abstract\&tlng=pt }\end{array}$ \\
\hline 12 & $\begin{array}{l}\text { Desenvolvimento de am- } \\
\text { biente virtual de aprendi- } \\
\text { zagem para a capacitação } \\
\text { em parada cardiorrespi- } \\
\text { ratória }\end{array}$ & $\begin{array}{l}\text { Silva AC, Ber- } \\
\text { nardes A., Évora } \\
\text { YDM, Dalri MCB, } \\
\text { Silva AR, Sampaio } \\
\text { CSJC. }\end{array}$ & 2016 & $\begin{array}{l}\text { Scielo } \\
\text { http://www.scielo.br/pdf/ } \\
\text { reeusp/v50n6/pt 0080- } \\
\underline{\text { 6234-reeusp-50-06-00990. }} \\
\text { pdf }\end{array}$ \\
\hline 13 & $\begin{array}{l}\text { Diário de bordo: expe- } \\
\text { riência de ensino-apren- } \\
\text { dizagem de gestão e } \\
\text { gerenciamento em saúde e } \\
\text { enfermagem } \\
\end{array}$ & $\begin{array}{l}\text { Santos JLG, Pes- } \\
\text { tana AL, Guerrero } \\
\text { P., Klock P., Erd- } \\
\text { mann AL. }\end{array}$ & 2013 & $\begin{array}{l}\text { Lilacs } \\
\text { http://www.periodicos. } \\
\text { ufc.br/rene/article/ } \\
\underline{\text { view/3561 }}\end{array}$ \\
\hline 14 & $\begin{array}{l}\text { Discurso sobre anatomia } \\
\text { humana no currículo inte- } \\
\text { grado de enfermagem }\end{array}$ & $\begin{array}{l}\text { Silva PS, Dias SL, } \\
\text { Henriques JCF, } \\
\text { Soares EF, Figuei- } \\
\text { redo NMA. }\end{array}$ & 2013 & $\begin{array}{l}\text { Lilacs } \\
\underline{\text { http://www.redalyc.org// }} \\
\underline{\mathrm{html} / 5057 / 505750897002 /}\end{array}$ \\
\hline
\end{tabular}




\begin{tabular}{|c|c|c|c|c|}
\hline 15 & $\begin{array}{l}\text { Educação em enferma- } \\
\text { gem: avaliação da forma- } \\
\text { ção por egressos, empre- } \\
\text { gadores e docentes }\end{array}$ & $\begin{array}{l}\text { Meira MDD, Kur- } \\
\text { cgant P. }\end{array}$ & 2015 & $\begin{array}{l}\text { Scielo } \\
\text { http://www.scielo.br/ } \\
\underline{\text { scielo.php?pi- }} \\
\underline{\mathrm{d}=S 0034-716720} \\
\underline{16000100016} \\
\underline{\text { \&script }=\text { sci abstract\& }} \\
\underline{\text { tlng=es }}\end{array}$ \\
\hline 16 & $\begin{array}{l}\text { Ensino das habilidades do } \\
\text { pensamento crítico por } \\
\text { meio de problem based } \\
\text { learning }\end{array}$ & $\begin{array}{l}\text { Carbogim FC, } \\
\text { Oliveira LB, Men- } \\
\text { donça ET, Mar- } \\
\text { ques DA, Friedri- } \\
\text { ch DBC, Püschel } \\
\text { VAA. }\end{array}$ & 2017 & $\begin{array}{l}\text { Scielo (Lilacs)* } \\
\underline{\text { http://www.redalyc.org// }} \\
\underline{\text { articulo.oa?id }=71453540015}\end{array}$ \\
\hline 17 & $\begin{array}{l}\text { Entre o velho e o novo: } \\
\text { avanços e desafios na } \\
\text { construção/reconstrução } \\
\text { de currículo de enferma- } \\
\text { gem }\end{array}$ & $\begin{array}{l}\text { Netto L., Silva } \\
\text { KL. }\end{array}$ & 2017 & $\begin{array}{l}\text { Lilacs } \\
\text { http://seer.ufsj.edu.br/ } \\
\text { index.php/recom/article/ } \\
\underline{\text { view/1634 }}\end{array}$ \\
\hline 18 & $\begin{array}{l}\text { Estratégia problematiza- } \\
\text { dora: relato de experiência } \\
\text { na disciplina processo de } \\
\text { cuidar em enfermagem } \\
\text { psiquiátrica }\end{array}$ & $\begin{array}{l}\text { Campos CJG, } \\
\text { Sobral FR. }\end{array}$ & 2013 & $\begin{array}{l}\text { Lilacs } \\
\text { http://www.periodicos. } \\
\text { ufc.br/rene/article/ } \\
\underline{\text { view } / 3647}\end{array}$ \\
\hline 19 & $\begin{array}{l}\text { Experiência de discentes } \\
\text { de enfermagem em meto- } \\
\text { dologias ativas na ativida- } \\
\text { de de ensino docente }\end{array}$ & $\begin{array}{l}\text { Brito LS, Ribeiro } \\
\text { LS, Ulisses LO, } \\
\text { Ortiz MFA, Whi- } \\
\text { taker MCO. }\end{array}$ & 2017 & $\begin{array}{l}\text { Lilacs } \\
\text { https://portalseer.ufba. } \\
\text { br/index.php/enfermagem } \\
\text { /article/view/21715 }\end{array}$ \\
\hline 20 & $\begin{array}{l}\text { Formação dialógica e par- } \\
\text { ticipativa na enfermagem: } \\
\text { contribuição ao desenvol- } \\
\text { vimento do pensamento } \\
\text { crítico-reflexivo e criativo } \\
\text { de acadêmicos }\end{array}$ & $\begin{array}{l}\text { Winters JFR, Pra- } \\
\text { do LM, Kempfer } \\
\text { RWSS. }\end{array}$ & 2017 & $\begin{array}{l}\text { Lilacs } \\
\text { http://www.reme.org.br } \\
\text { artigo/detalhes/1205 }\end{array}$ \\
\hline 21 & $\begin{array}{l}\text { Novas possibilidades para } \\
\text { o ensino de enfermagem } \\
\text { em saúde mental: uma } \\
\text { experiência de monitoria }\end{array}$ & $\begin{array}{l}\text { Freitas KFS, Oli- } \\
\text { veira MFV, Lopes } \\
\text { MMB, Garcia TE, } \\
\text { Santos MS, Dias } \\
\text { GAR. }\end{array}$ & 2014 & $\begin{array}{l}\text { Lilacs } \\
\text { http://periodicos.ufc.br } \\
\text { rene/article/view/3269 }\end{array}$ \\
\hline
\end{tabular}




\begin{tabular}{|c|c|c|c|c|}
\hline 22 & $\begin{array}{l}\text { O ensino de primeiros so- } \\
\text { corros sob a ótica de um } \\
\text { currículo de orientação } \\
\text { problematizadora }\end{array}$ & $\begin{array}{l}\text { Marque MD, Lo- } \\
\text { pes Júnior CL, } \\
\text { Bomfim EO, Go- } \\
\text { mes CPML, Pavel- } \\
\text { queire S. } \\
\end{array}$ & 2014 & $\begin{array}{l}\text { Lilacs } \\
\text { http://www.redalyc.org/ } \\
\underline{\text { articulo. }} \\
\text { oa?id=505750770015 } 2\end{array}$ \\
\hline 23 & $\begin{array}{l}\text { O ensino de saúde mental } \\
\text { na graduação de enferma- } \\
\text { gem: um estudo de caso }\end{array}$ & $\begin{array}{l}\text { Villela JC, Maftum } \\
\text { MA, Paes MR. }\end{array}$ & 2013 & $\begin{array}{l}\text { Scielo (Lilacs)* } \\
\text { http://www.scielo.br/ } \\
\text { scielo.php?pid=S0104- } \\
\underline{07072013000200016 \&} \\
\text { script=sci abstract\&tlng=pt }\end{array}$ \\
\hline 24 & $\begin{array}{l}\text { O legado do cuidado } \\
\text { como aprendizagem re- } \\
\text { flexiva }\end{array}$ & $\begin{array}{l}\text { García MR, Moya } \\
\text { JLM. }\end{array}$ & 2016 & $\begin{array}{l}\text { Scielo } \\
\text { http://www.scielo.br/ } \\
\text { pdf/rlae/v24/pt } \\
\underline{0104-1169-r l a e-24-0271} \\
\underline{1 . p d f}\end{array}$ \\
\hline 25 & $\begin{array}{l}\text { Prática avaliativa na aten- } \\
\text { ção básica: revisitando a } \\
\text { pedagogia da problema- } \\
\text { tização }\end{array}$ & $\begin{array}{l}\text { David HL, Camar- } \\
\text { go Júnior KR. }\end{array}$ & 2013 & $\begin{array}{l}\text { Lilacs } \\
\text { https://www.e-publicacoes. } \\
\text { uerj.br/ojs/index.php/ } \\
\text { enfermagemuerj/article/ } \\
\text { view/10054 }\end{array}$ \\
\hline 26 & $\begin{array}{l}\text { Problemas éticos vivencia- } \\
\text { dos no estágio curricular } \\
\text { supervisionado em enfer- } \\
\text { magem de um currículo } \\
\text { integrado }\end{array}$ & $\begin{array}{l}\text { Bracialli JCBLAD, } \\
\text { Oliveira MAC. }\end{array}$ & 2013 & $\begin{array}{l}\text { Scielo (Lilacs)* } \\
\text { http://www.scielo.br/ } \\
\text { scielo.php?pid=S0080- } \\
\text { 62342013000400937 } \\
\text { \&script=sci abstract\&tl- } \\
\text { ng=pt }\end{array}$ \\
\hline 27 & $\begin{array}{l}\text { Simulação por computa- } \\
\text { dor e em laboratório no } \\
\text { ensino em enfermagem } \\
\text { neonatal: as inovações e o } \\
\text { impacto na aprendizagem }\end{array}$ & $\begin{array}{l}\text { Fonseca LMM, } \\
\text { Aredes NDA, } \\
\text { Fernandes AM, } \\
\text { Batalha LMC, } \\
\text { Apóstolo JMA, } \\
\text { Martins JCA, Ro- } \\
\text { drigues MA. }\end{array}$ & 2016 & $\begin{array}{l}\text { Scielo } \\
\text { http://www.scielo.br/ } \\
\text { pdf/rlae/v24/pt } \\
\text { 0104-1169-rlae-24- } \\
\underline{\text { 02808.pdf }}\end{array}$ \\
\hline
\end{tabular}




\begin{tabular}{|l|l|l|l|l|}
\hline 28 & $\begin{array}{l}\text { Tecnologia no ensino de } \\
\text { enfermagem }\end{array}$ & $\begin{array}{l}\text { Salvador PTCO, } \\
\text { Martins CCF, Al- } \\
\text { ves KYA, Pereira } \\
\text { MS, Santos VEP, } \\
\text { Tourinho FSV. }\end{array}$ & 2016 & $\begin{array}{l}\text { Lilacs } \\
\text { https://portalseer. } \\
\text { ufba.br/index.php/ } \\
\underline{\text { enfermagem/article/ }} \\
\text { view/9883 }\end{array}$ \\
\hline 29 & $\begin{array}{l}\text { Uso de dinâmica de grupo } \\
\text { como estratégia de abor- } \\
\text { dagem do tema liderança } \\
\text { saudável }\end{array}$ & $\begin{array}{l}\text { Gvozd R., Pissi- } \\
\text { nati PSC, Haddad } \\
\text { MCFL, Montezeli } \\
\text { JH. }\end{array}$ & 2017 & $\begin{array}{l}\text { Lilacs } \\
\underline{\text { http://seer.ufsj.edu. }} \\
\underline{\text { br/index.php/recom }} \\
\text { Larticle/view/1262 }\end{array}$ \\
\hline
\end{tabular}

Fonte: Dados da Pesquisa, 2018.

* Devido à simultaneidade dos artigos nos meios de buscas, optou-se por manter os achados do portal de revistas Scientific Electronic Library Online (SCIELO) pela sua facilidade e praticidade de busca e não descartar a identificação dos artigos da base de dados Literatura Latino-Americana em Ciências de Saúde (LILACS) por ter participado do processo de seleção dos artigos, indiferentemente da duplicidade.

\section{Análise dos resultados}

Após as leituras em profundidade dos artigos selecionados, o processo de sumarização permitiu a definição, criação e organização dos mesmos nas seguintes categorias de análise: Categoria 1 - Metodologias ativas associadas à tecnologia e ao processo de aprendizagem; e Categoria 2 - O protagonismo discente/docente. Os artigos que compõem tais categorias estão dispostos na Tabela 1 a seguir:

Tabela 1 - Sumarização* das discussões identificadas nos artigos.

\begin{tabular}{l|l}
\hline \multicolumn{1}{c|}{ Categorias de análise } & \multicolumn{1}{c}{ Artigos selecionados } \\
\hline Metodologias ativas associadas à tec- & $1,2,3,4,5,6,8,9,11,12,16,19,22$, \\
nologia e ao processo de aprendizagem & $23,25,27,28,29$ \\
O protagonismo discente/docente & $7,10,13,14,15,17,18,20,21,24,26$. \\
\hline
\end{tabular}

Fonte: Dados da Pesquisa, 2018.

* Esta sumarização foi construída considerando os temas em maior discussão nos periódicos, assim, unificando os semelhantes e facilitando a análise. 
A seguir, serão discutidas nas categorias a temática proposta objetivando apresentar as discussões dos autores acerca das metodologias ativas associadas à tecnologia no âmbito educacional.

\section{Categoria 1: Metodologias ativas associadas à tecnologia e ao processo de aprendizagem}

O caráter dos processos de aprendizagem envolvidos nas práticas do ensino superior é passível de discussão. Direcionamentos a favor e contra processos educacionais de aprendizagem remetem a diversas discussões no âmbito educacional e no acadêmico, considerando a necessidade de inovação, mesmo que esta considere a lógica de mercado. Ao analisar a necessidade de inovação como potencializadora do ensino e, por consequência, como promotora de produções e patentes, a discussão é justificada pela necessidade motivacional do público envolvido.

Pereira et al. (2014) descrevem que o investimento profissional em educação permanente prevê a preparação dos profissionais, entre estes os da área da saúde. Objetiva-se responsabilidade, capacidade de tomada de decisões, autonomia e práticas de pensamento reflexivo sobre suas atribuições, prevendo melhorar o cuidado prestado ao paciente e à comunidade. A educação permanente utiliza problematização e aprendizagem significativa quando faz que o profissional compreenda sua realidade, deixando de ser um mero espectador ou cumpridor de ordens, sendo, por sua vez, realizada a partir de suas vivências, encaminha e orienta os trabalhadores pela necessidade de saúde da população.

Machado, Göttems e Pires (2013) concordam com Pereira et al. (2014) e identificam que os participantes da pesquisa, após submetidos à educação permanente, começam a desenvolver um olhar crítico e reflexivo sobre seu processo de trabalho, assim aumentam sua capacidade de identificação de erros, que, então, se tornam um desafio a ser enfrentado. Percebe-se que os protagonistas sentem-se inseridos no processo de trabalho, dedicam atenção ao estudo da teoria e da prática e desmistificam crenças aumentando 
saberes e autonomia. A educação permanente possui fragilidades, as quais devem ser enfrentadas como parte do mesmo.

A globalização e os processos de modernização à adesão da tecnologia no âmbito educacional direcionam a necessidade de criação de novos processos de aprendizagem para que haja concorrência à altura, dentro e fora das instituições de ensino, para atender às necessidades de formação profissional. Corroboram com a discussão Alves et al. (2015), em que a utilização de atividade lúdica como estratégia de ensino possibilita ao discente a experiência completa, associado ao ato, ao pensamento e ao sentimento. Souza et al. (2017) descrevem que atividades lúdicas, considerando sua prática descontraída, criativa e dinâmica, versam acerca de uma excelência em instrumento de ensino, oportunizando uma aprendizagem divertida, interessante e alegre.

Souza, Collicelli e Madureira (2017) descrevem que nessa prática é necessário que os participantes, quer discentes quer docentes, estejam impulsionados pela mudança, motivados, engajados e organizados. Dessa forma, a gincana teórica associada ao uso de tecnologias, como jogos digitais, possibilitou reflexão e construção de conhecimentos e saberes, propiciando aos estudantes a participação ativa na construção do seu conhecimento por meio de metodologias ativas.

Campos, Ribeiro e Depes (2014) reforçam que ainda que diversos benefícios sejam citados, a dificuldade de adesão às práticas de metodologias ativas associadas à tecnologias na educação existe. Citam o exemplo de um método denominado "Bricolagem", que propõe romper a prática monológica de fazer pesquisa, oportunizando interpretações variáveis. É relevante o reconhecimento das experiências prévias dos alunos na construção do conhecimento, logo, compreendem que essas informações e conceitos prévios podem ser valiosos tanto quanto pesquisas científicas e seus resultados, somatizados pela possibilidade de aprender não apenas com professores, mas também em discussões com colegas mediante troca de contribuições e relatos. Para que 
se obtenha um aprendizado significativo, é necessário estabelecer relação entre os saberes prévios e o novo, possibilitando a reflexão sobre conhecimento empírico e científico.

Destacamos que a teoria da Aprendizagem Baseada em Problemas visa romper com o método de educação bancária, da mesma forma que a metodologia ativa. Assim, os alunos se reconhecem como responsáveis pelo próprio aprendizado, além do despertar do senso crítico.

Reforçando as discussões dos autores mencionados, Carvalho et al. (2016) citam o conceito definido por Ausubel sobre essa teoria. De maneira mais clara, a aprendizagem significativa baseiase na aquisição e armazenamento de um conhecimento que deverá ser ancorado em um conhecimento prévio, funcionando como uma ponte cognitiva. Segundo Ausubel, a teoria da aprendizagem se caracteriza pela interação entre o novo conhecimento e as experiências prévias, fortalecendo o educando como agente ativo da construção de seu saber. Caracteriza-se por aprender fundamentado em perguntas e não em respostas.

Silva et al. (2013) descrevem ainda o desenvolvimento de revisão de uma ferramenta utilizada para o desempacotamento de produções acadêmicas. Esse instrumento denominado "Vê de Gowin" não se trata de uma grande novidade de tecnologia instrucional, diferente disso, é uma ferramenta não totalmente explorada ainda. $\mathrm{O}$ estudo afirma que existe desenvolvimento entre alunos, professores e materiais didáticos proporcionados pela utilização da ferramenta e, principalmente, pelo compartilhamento de significados, de modo que o aluno constrói seu caminho de aprendizagem, e então aprende a aprender.

Para Fonseca et al. (2013) e Goés et al. (2015), a relevância e a expoente participação da tecnologia digital no âmbito educacional em saúde são inquestionáveis. A cada dia a internet circunda as rotinas diárias, não sendo diferente na formação do processo de ensino. A criação de recursos educacionais tecnológicos e a tecnologia educacional compõem uma ferramenta complementar 
do ensino, por vez não excluindo métodos tradicionais, mas corroborando para uma formação de sucesso da construção do conhecimento, já que torna o processo mais dinâmico, criativo e atraente. No ensino em enfermagem, a utilização de ferramentas tecnológicas digitais pode acarretar em uma maior facilidade do pensamento crítico e reflexivo do estudante.

Silva et al. (2016) discutem que os recursos tecnológicos servem de estratégias para que o aprendizado seja produtivo e agradável, mas sem perder o seu objetivo principal de difusão de conhecimentos. Sendo assim, usar como estratégia a educação permanente mediada pelo computador pode ser uma alternativa eficaz de fixação do aprendizado, devido ao fato de o usuário ter a possibilidade de obter uma avaliação do seu conhecimento adquirido com interatividade.

Carbogim et al. (2017) realizaram uma pesquisa aplicada a 102 estudantes do curso de graduação de enfermagem em uma universidade federal do Brasil. Foram divididos aleatoriamente em dois grupos, sendo um de controle e outro de intervenção, tendo o segundo participado de atividade com mediação tecnológica. O desenvolvimento do curso com a aplicação de problematização seguiu os pressupostos de Berbel. Como resultado, observaram-se que, ambos os grupos, mobilizaram habilidades de pensamento crítico, no entanto, os participantes do grupo de intervenção apresentaram maior clareza na percepção sobre pensamento crítico, aproximandose dos resultados descritos na literatura. Os autores asseveram que o resultado vai ao encontro com as teorias histórico-culturais, logo, o aprendizado de maior sucesso é aquele que permite a interação entre atividades do processo de aprendizagem e sua apropriação do conhecimento por variáveis diversas como a tecnologia.

Brito et al. (2017) sinalizam que as Diretrizes Curriculares Nacionais do Curso de Enfermagem contemplam a necessidade de desenvolver habilidades vinculadas à educação permanente no acadêmico de enfermagem, por exemplo, de cursos voltados às especificidades desse público. Este visa formar um profissional 
capacitado para planejar e desenvolver atividades de educação em sua população, comunidade, equipe e trabalhadores do seu meio.

Marque et al. (2014) descrevem o conhecimento de estudantes dos cursos de medicina e de enfermagem, relacionado à temática de primeiros socorros, antes e após a realização do treinamento norteado por metodologias ativas de ensino-aprendizagem, sendo utilizada a problematização e tecnologias educacionais como ferramentas de estratégias válidas de capacitação. No pós-teste, foi verificado o aprendizado dos participantes, tendo em vista que a maioria demonstrou conhecimentos frente às situações de primeiros socorros que lhes foram apresentados via casos clínicos virtuais. Demonstrou-se assim que a aprendizagem significativa busca funcionalidade e relevância para a prática, e é ancorada pela integração construtiva de conhecimentos, habilidades e atitudes que possibilitam a articulação do aprender a aprender, num processo de ação-reflexão-ação.

Villela, Maftum e Paes (2013) relatam que os docentes de enfermagem, principalmente os da área da saúde mental, devem utilizar as mais variadas técnicas e metodologias ativas, permitindo que os estudantes adquiram novos conhecimentos e formas de aprendizagem, para que futuramente as metodologias usadas pelos professores gerem uma memória fiel por meio de uma consciência crítica. Os docentes devem estimular uma aprendizagem autônoma, sendo os estudantes os responsáveis pela construção de seu próprio conhecimento. Estes concordam com os autores anteriores em que a diversidade e a aplicação de práticas de ensino voltadas à aproximação da realidade apresentam maior relevância quando avaliadas.

De acordo com o exposto, David e Camargo Júnior (2013) relatam que foram realizados estudos de Linhas de Base por meio de oficinas de capacitação para Atenção Básica, para a incorporação de metodologias sobre a utilização de ferramentas avaliativas no dia a dia dos trabalhadores das equipes de saúde da família. A avaliação da saúde se baseava num conceito tecnicista e burocrático, com metas, indicadores e sem discussões aprofundadas. O objetivo foi 
desenvolver estratégias pedagógicas, permitindo ao grupo um avanço acerca do processo de reflexão crítica a respeito da realidade da atenção básica, permitindo assim a participação e a sustentabilidade de ações contínuas e sistemáticas das avaliações, colaborando nas definições da estrutura e desenvolvimento das oficinas por meio da pedagogia problematizadora, com ações de aprendizagem que respeitassem as especificidades locais e culturais. Por intermédio da utilização dessa ferramenta, com os preceitos da metodologia ativa, os profissionais tiveram mais autonomia, tornando-se profissionais mais flexíveis e tecnicamente competentes, sendo capazes de construir novos modos de fazer saúde pela troca de conhecimentos técnicos-científicos e com uso da criatividade.

Fonseca et al. (2016) descrevem a avaliação e a aprendizagem cognitiva de 14 estudantes de enfermagem na avaliação clínica neonatal a partir do uso de simulação por computador em laboratório. Verificaram-se as vantagens de associar as diversas ferramentas educacionais e não utilizá-las isoladamente, devendo assim lançar mão de estratégias inovadoras e criativas durante o processo de ensino-aprendizagem, como apontam estudiosos que avaliaram a relevância de tecnologias de ensino articuladas às metodologias ativas de aprendizagem. Os jovens da atualidade aprendem com maior facilidade quando em contato com a tecnologia, com as tarefas em grupo ancoradas em experiências e problemas e com o aprendizado colaborativo e interativo. Tal estudo confirma e concorda com as discussões anteriores quando da necessidade de incorporação de metodologias inovadoras e da tecnologia no ensino.

Salvador et al. (2016) apresentam e discutem a relevância acerca das possibilidades e benefícios do uso de ferramentas tecnológicas no ensino da enfermagem, onde estas são capazes de qualificar práticas de ensino mediante uma visão de coparticipação entre docente e discente mediada pela interatividade e pela criatividade. Foram citadas algumas possibilidades tecnológicas que podem ser incorporadas ao ensino do enfermeiro, qualificando o processo de ensinar/aprender por meio da promoção de um 
ambiente inovador, crítico e reflexivo, são eles: e-portfólio, webpodcasting, wiki, special interest group (SIG), tele-enfermagem, simulação realística, objective structured clinical evaluation (OSCE), teleimersão e ambientes virtuais. Usando da teoria andragógica, o educador passa a enxergar os alunos como participantes ativos do processo de ensino-aprendizagem, o que pode vir a facilitar a interação e integração desse processo. No ensino da enfermagem, esse processo torna-se mais complexo à medida que se entende que o futuro profissional deve ser formado não somente para técnicas e teoria, mas que é fundamental a formação enquanto ser humano e cuidador de si e de outros. Sendo assim, para que a aprendizagem seja realmente significativa, o processo de ensino deve envolver estratégias inovadoras e adequadas para tal finalidade. Os autores corroboram os demais e concordam que as ações inovadoras apresentadas são exemplos que aliam a tecnologia e o ensino para produzir um modelo de processo adequado e produtor de aprendizados significativos para discentes e docentes.

Enfatizada por Gvozd et al. (2017), as metodologias ativas despertam a curiosidade e que a problematização traz como resultados novos conhecimentos e promove o desenvolvimento dos estudantes. A superação de desafios é o que impulsiona a aprendizagem de adultos, o que contribui para o desenvolvimento de habilidades e competências para o trabalho em saúde, sendo reforçada pelos demais autores debatidos.

\section{Categoria 2: O protagonismo discente/docente}

Nessa categoria, o papel dos protagonistas envolvidos no âmbito da educação é fundamental na construção do processo de aprendizagem. Habilidades de discentes e de docentes são necessárias para que o processo se desenvolva, considerando todas as possibilidades, desde ferramentas tecnológicas até as comportamentais e relacionais.

Diante do exposto, Ide et al. (2014) dizem que, para uma trajetória acadêmica de formação sólida, é necessário organização 
curricular adequada, enfatizando os papéis dos alunos, e do professor, como facilitadores do processo de ensinar-aprender. A construção de um currículo integrado na utilização das metodologias ativas deve privilegiar experiências interpessoais de sala de aula e da comunidade, pois essa imersão desenvolve consciência crítica e reflexiva. Cogo et al. (2016) descrevem que a educação vem sendo contemplada por um discurso de mudanças curriculares e os professores procuram métodos de ensino que despertem o interesse e que desenvolvam a aprendizagem dos estudantes. A incorporação de metodologias como a aprendizagem ancorada em problemas e a tecnologia, por intermédio dos casos de papel e role play, desenvolveram situações amparadas na realidade, que apresentaram resultados criativos e inovadores pelos estudantes, estimulando o trabalho em grupo e a inter-relação.

As metodologias ativas vêm sendo implementadas no currículo do ensino de enfermagem, para que os profissionais sejam críticos, reflexivos, possuam proatividade perante as demandas do mercado de trabalho e que estejam preparados a "aprender a aprender". Diante do exposto, Santos et al. (2013) relatam a experiência vivida por um grupo de pós-graduandos em estágio de docência em uma instituição federal de ensino. Foram utilizados "Diários de Bordo", onde os alunos expuseram suas expectativas sobre o referido estágio e após foram relatando as vivências diárias.

Silva et al. (2013) discutem o currículo integrado. Com isso, foram associadas medidas pedagógicas que rompem a pedagogia transversal que está quase sempre presente nas salas de aula alterando o protagonismo do discente e do docente na construção do ensino.

Os autores Meira e Kurcgant concordam que essa modalidade de currículo é um desafio aos educadores (2015), ao apontar um caminho para a formação protagonizada pelo aluno. Logo, quando o aluno é responsabilizado por sua aprendizagem, lhe é conferido a autonomia de busca para respostas e, então, gera um processo de aprendizagem significativa. Considerando, inclusive, que a participação de egressos, empregadores e docentes nessa reflexão 
e discussão é significativa para a reorganização curricular sobre as demandas e deficiências apontadas.

Netto e Silva (2017) descrevem a construção e a implementação de uma nova proposta curricular baseando-se em um projeto pedagógico inovador que unificou os estudantes de medicina e enfermagem por quatro períodos. Esta é similar à proposta dos autores anteriores sobre o currículo integrado, o qual gera maior desenvolvimento por parte de discentes e docentes em todo o processo de ensino. Os autores destacam que, para a realização e implementação de um novo modelo assistencial de ensino, é necessário mobilizar a prática reflexiva para favorecer a aprendizagem e a prática de ações assistenciais integradas em contextos complexos.

Campos e Sobral (2013) discutem a experiência de alunos de Enfermagem, alicerçando-se em uma metodologia ancorada em problemas. A experiência dos alunos usou o Arco de Maguerez, dividido em cinco etapas. A primeira se caracterizava em observar o cenário para detecção dos problemas. Eles descrevem a maior frequência da implantação de novas metodologias de ensino nas aulas da graduação e o quanto isso é benéfico. Em contrapartida, foram detectadas algumas dificuldades, principalmente pelo aluno estar acostumado com uma metodologia vertical, usada cotidianamente.

Com os potenciais de instigar o aluno à curiosidade e reflexão, motivar a sua autonomia no processo de ensino e incentivar a participação nos exercícios do aprender, as metodologias ativas fazem do professor um facilitador do processo de aprendizagem. Winters et al. (2017) afirmam que revisões a partir das mudanças curriculares nacionais apenas incorporam conceitos das pedagogias, logo, não apresentam um comprometimento real com as alterações propostas, sendo um desafio contínuo.

Freitas et al. (2014) descrevem a necessidade de formação de profissionais preocupados com os problemas da nossa sociedade, os quais necessitam de empenho e determinação para o enfrentamento 
dos mesmos. Logo, os métodos de ensino, na atualidade, devem ofertar aos alunos uma educação flexível, crítica, versátil e articulada ao campo de trabalhos e seus subsunçores.

$\mathrm{Na}$ realidade da prática profissional, continua-se a replicar e imitar as ações e condutas de outros profissionais, questionar-se sobre como e por que realizar acaba por ser uma prática inovadora que permite refletir a respeito de nossos paradigmas, quando as atividades profissionais da enfermagem se relacionam com funções complexas. Isto é observado no estudo de García e Moya (2016), em que algumas das temáticas de maior significância como a interrogação didática, uma prática que exige do tutor e aluno uma conexão mental para que a indução à reflexão e às interpretações leve os alunos a diagnosticar suas compreensões, que por vezes não é valorizada enquanto reflexiva.

Para Bracialli e Oliveira (2013), trabalhar métodos de ensino como a problematização oportuniza ao aluno a reflexão sobre possíveis situações reais que existirão em sua jornada de trabalho. Logo, os futuros profissionais devem, além de receber formação técnica, desenvolver responsabilidade social. Tais achados enfatizam as discussões anteriores sobre as habilidades e responsabilidades de discentes e docentes durante a formação profissional e do processo de ensino.

\section{Considerações finais}

Em ambas as categorias de análise há concordância dos autores acerca da necessidade de alteração das práticas de ensino, considerando a necessidade de inovação e de práticas que utilizem a tecnologia na obtenção de resultados desse processo. Mesmo que o uso de metodologias ativas apresente resultados satisfatórios ao longo das práticas de ensino, estas ainda demandam desafios e readequações de acordo com a capacidade dos profissionais e das instituições. Da mesma forma que a tecnologia isoladamente não garante o sucesso do processo de aprendizagem, mas possui ampla contribuição e responsabilidade pela diversificação do processo de aprendizagem no âmbito educacional. 
Observou-se que as práticas acerca de um currículo integrado são apoiadas assim como devem atentar para as habilidades de autonomia, protagonismo e integração discente/docente no processo de ensino.

Considerando a atual geração de adolescentes e crianças, que já utilizam a tecnologia para o aprendizado, inclusive em ambiente não escolar, as discussões acerca dessa inserção não são passíveis de retrocesso. Pensar os processos de inserção da tecnologia é tarefa sine qua non da aprendizagem moderna, considerando que proporcionam, em sua maioria, ambientes que se aproximam ao da prática profissional.

\section{Referências}

AUSUBEL, D. P. Educational Psychology: A Cognitive View. New York: Holt, Rinehart and Winston, 1968.

BERBEL, Neusi Aparecida Navas. As metodologias ativas e a promoção da autonomia de estudantes, 2011.

BEZ, M. R. Construção de um Modelo para o Uso de Simuladores na Implementação de Métodos Ativos de Aprendizagem das Escolas de Medicina. Porto Alegre, 2013, 314s. Tese (Doutorado em Informática na Educação) - PGIE/ UFRGS, Porto Alegre, 2013.

COOPER, H. M. Scientific guidelines for conducting integrative research reviews. Review of Educational Research, v. 52, n. 2, p. 291-302, 1982.

FREIRE, P. Pedagogia da Autonomia: Saberes Necessários à Prática Educativa. São Paulo: Paz e Terra, 1996.

MENDES, K. D. S.; SILVEIRA, R. C. C. P.; GALVÃO, C. M. Revisão integrativa: método de pesquisa para a incorporação de evidências na saúde e na enfermagem. Revista Texto e Contexto Enfermagem, Florianópolis, v. 17, n. 4, p. 758-64, 2008.

MOHER, D. et al. Preferred Reporting Items for Systematic Reviews and MetaAnalyses: The PRISMA Statement. PLoS Med., v. 6, n. 7, 2009. Disponível em: http://prisma-statement.org/PRISMAStatement/FlowDiagram.aspx. Acesso em: 20 set. 2017. 
PADOVANI, O., CORRÊA, A. K. Currículo e Formação do Enfermeiro: Desafios das Universidades na Atualidade. Saúde \& Transformação Social Change. Acesso em: 20 mar. 2018.

ROsSO, A.; TAGBLIEBER, J. (1992). Métodos Ativos e Atividades de Ensino. Perspectiva - Revista do Centro de Ciências e Educação, 10, 17.

ZIV, A.; David, B.; ZIV, M. Simulation Based Medical Education: an opportunity to learn from errors. Medical Teacher, v. 27, n. 3, p. 193-199, 2005.

Submetido em: 22-10-2018

Aceito em: 23-11-2018 